\title{
A Study on the Improving of CFT Column's Structure and Durability Performance
}

\author{
Dongun Lee, Daegeon Kim
}

\begin{abstract}
This paper investigates the contribution of rib elements attached inner side of CFT for higher bond strength between steel tube and concrete and fire performance with no protections. Test results also present the work of beam' s shape to fire resistance, the microstructure of concrete and the benefit of a paper drain that can be letting the redundant water out through the holes drilled on the tube plate. Discussions on beam' $s$ design could be followed after some more fire tests accordingly conducted within this investigation.
\end{abstract}

Keywords-CFT column, tube plate, fire resistance, structure, durability

\section{Introduction}

The concrete filled steel pipe(CFT) structure is a structural system that exhibits excellent properties in terms of stiffness, proof strength, deformation performance, refractoriness and construction because the steel pipe confines the concrete inside.[1] Research is underway to reinforce reinforcing bars and plates for the purpose of improving the fireproofing performance of CTF columns. In this reinforcement method, the flat plate reinforcement is buckled when the compressive force is applied, so that the plate is arranged at regular intervals.[2] However, it is known that when the reinforcement amount is increased, the construction cost is increased and the workability is decreased due to the amount of steel material. In this study, to improve the performance of CFT columns, we study the shape of inner ribs to compensate the disadvantages of existing methods.

\section{Structural Performance of CFT}

The general design concept of CFT compressors includes the strength of steel pipe, filled concrete and inner reinforcement. The first is to reinforce the concrete by reinforcing the concrete inside the concrete filled steel pipe column using the large steel pipe, and the second is to reinforce the reinforcing steel in order to improve the refractory performance of the concrete filled steel pipe column. However, in this case, the compressive strength is treated as a separate problem, steel pipes and the concrete filling has been assumed to be fully synthesized.[3]

Dongun Lee

Dongseo University

Republic of Korea

Daegeon Kim

Dongseo University

Republic of Korea
Table 1 below shows the comparison of the width-tothickness ratio limits specified in each standard. AISCLRFD, ACI, BS5400 and EC4 have the same or similar results.[4]

However, AIJ (Japan Institute of Architects) relaxed the limit of thickness ratio of existing steel pipe design to 1.5 times. This is based on the results of a study on the effect of filled concrete on the local buckling about plate elements of steel pipes. However, the background of this type of experiment is the use of relatively small-sized steel tubes, which are not yet recognized internationally.

TABLE I. COMPARISON OF WIDTH-THICKNESS RATIO OF VARIOUS COUNTRIES

\begin{tabular}{|c|c|c|c|c|c|}
\hline & $\begin{array}{l}\text { AISC- } \\
\text { LRFD }\end{array}$ & ACI & EC4 & BS5400 & AIJ \\
\hline $\begin{array}{c}\text { Square } \\
\text { steel } \\
\text { pipe } \\
\mathrm{D} / \mathrm{t}\end{array}$ & $\begin{array}{c}\sqrt{\frac{3 E_{s}}{F_{s}}} \\
(51.2)\end{array}$ & $\begin{array}{l}\sqrt{\frac{3 E_{s}}{F t}} \\
(51.2)\end{array}$ & $\begin{array}{l}\frac{81}{\sqrt{F_{\mathrm{v}}}} \\
(52.2)\end{array}$ & $\begin{array}{l}\sqrt{\frac{3 E_{s}}{F_{u}}} \\
(51.2)\end{array}$ & $\begin{array}{c}1.6 \times \frac{74}{\sqrt{F_{\mathrm{v}}}} \\
(71.7)\end{array}$ \\
\hline $\begin{array}{c}\text { Round } \\
\text { steel } \\
\text { pipe } \\
\mathrm{D} / \mathrm{t}\end{array}$ & $\begin{array}{c}\sqrt{\frac{8 E_{s}}{F_{t}}} \\
(83.7)\end{array}$ & $\begin{array}{c}\sqrt{\frac{8 E_{s}}{F t}} \\
(83.7)\end{array}$ & $\frac{216}{F_{\text {v }}}$ & $\begin{array}{l}\sqrt{\frac{8 E_{s}}{F_{u}}} \\
(83.7)\end{array}$ & $\begin{array}{c}1.6 \times \frac{240}{F_{\mathrm{v}}} \\
(150)\end{array}$ \\
\hline
\end{tabular}

* The numerical value is the yield strength $=2.4 \mathrm{tf} / \mathrm{cm}^{2}$.

The allowable stress laws of the United States AISCASD (9th Ed.) Has not been presented in the design expression of the compression members of the CFT. However, according to documents in 1979 it has been proposed by the sum of the square pipes and distinction compressive strength of concrete and steel pipe yield strength without $0.85 \mathrm{fck}$ Ac circular tube and apply the same safety factor. Therefore, concrete filled square pipes do not place a further increase of the strength and confining effect on the circular tube compressed material than the compression member.[5]

\section{Development of the Inner Steel Tube Attached to the Stiffener}

The CFT structure is a structural system that exhibits excellent properties in terms of stiffness, proof strength, deformation performance, refractoriness and construction because the steel pipe confines the concrete inside. Research is underway to reinforce reinforcing bars and plates for the purpose of improving the fireproofing performance of $\mathrm{CTF}$ columns. In this reinforcement method, the flat plate 
reinforcement is buckled when the compressive force is applied, so that the plate is arranged at regular intervals. However, it is known that when the reinforcement amount is increased, the construction cost is increased and the workability is decreased due to the amount of steel material. In this study, to improve the performance of CFT columns, we study the shape of inner ribs to compensate the disadvantages of existing methods.

\section{A. Reinforcement CFT Column Specimen Fabrication}

In this study, Corrugated web attached to inner surface of steel pipe for refractory performance test was attached to inside of steel-tube by automatic machine welding of domestic D company, which is a corrugated beam production and processing company. The strength and energy absorption capacity are superior to other structural systems due to the effect of preventing local buckling of the square tube web, and it can be expected to greatly reduce the construction cost and labor cost by omitting the refractory covering material during construction. CFT was produced in the test piece attached to the ribs of the developed shape for the fire resistance tests of the column. Placing a sensor for temperature measurement section with a steel pipe assembly was used a high-strength concrete mix design.

\section{B. Fabrication of Pipe}

The CFT column specimen was designed as shown in Fig. 1, and the plate and web material of the steel pipe were processed and assembled in order.

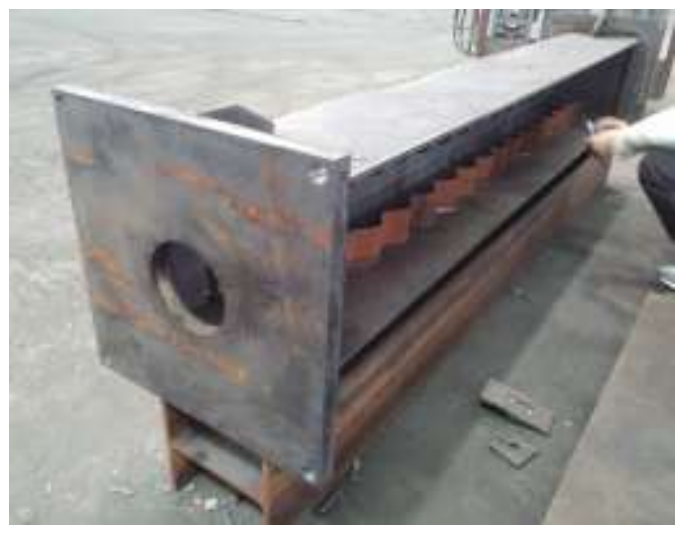

(a) Top surface of test specimen

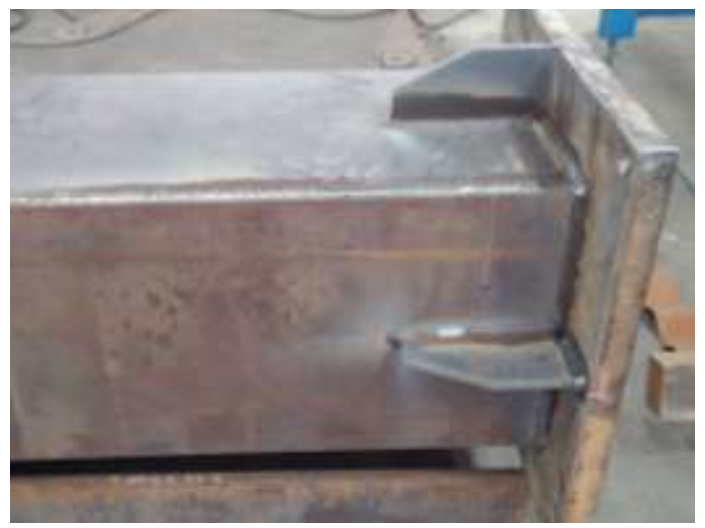

(b) Lower test piece (plate, rib)

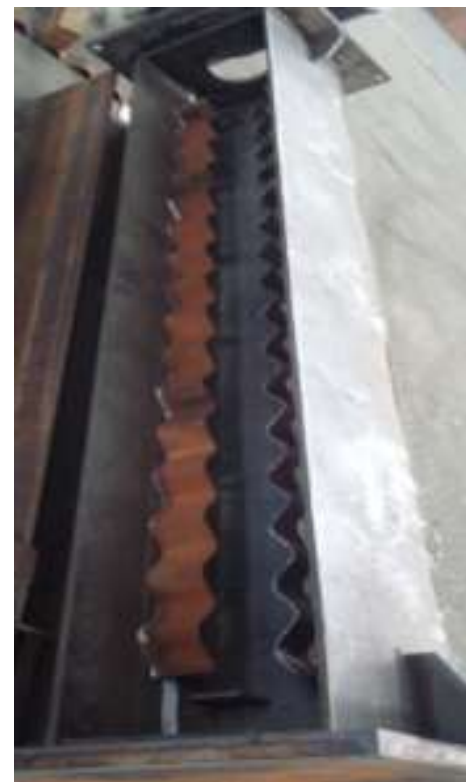

(c) 3-sided assembly status

Figure 1. Plate assembly of column specimen

\section{Concrete Mixing and Placing}

The CFT column concrete of $40 \mathrm{MPa}$ class was designed and installed for the preparation of test specimens. Figure 2 shows a flash concrete test after mixing concrete. A mixer with a design strength of $40 \mathrm{MPa}$ was used and fibers (nylon fiber) were mixed in order to reduce the heat of high strength concrete at high temperature. For the comparative study, high strength concrete without fiber was used as a control specimen. Table 2 shows the results of the material test.

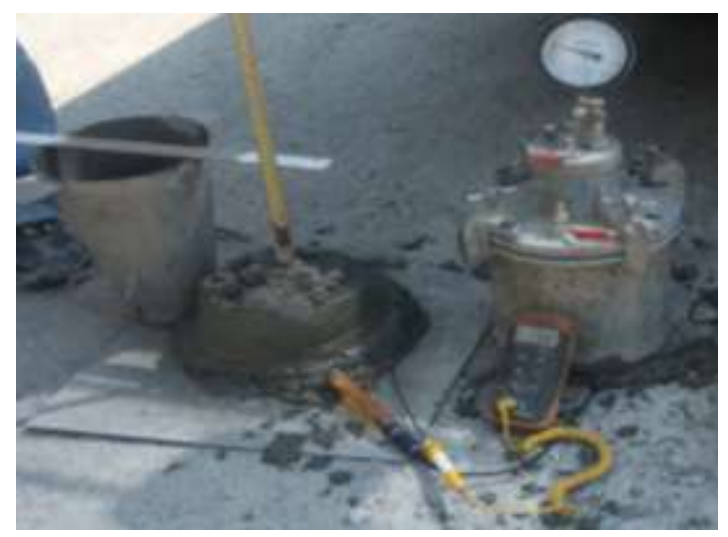

Figure 2. Results of Material test

TABLE II. CONCRETE MATERIAL TEST VALUE

\begin{tabular}{|c|c|l|c|c|}
\hline Specification & $\begin{array}{c}\text { Air } \\
\text { volume }\end{array}$ & slump & $\begin{array}{c}\text { Amount of } \\
\text { chloride }\end{array}$ & $\begin{array}{c}\text { Concrete } \\
\text { temperature }\end{array}$ \\
\hline $25-40-$ & $4.8 \%$ & $160 \mathrm{~mm}$ & $0.12 / \mathrm{m}^{3}$ & $19.8^{\circ} \mathrm{C}$ \\
\hline 150 & & & \\
\hline
\end{tabular}




\section{Iv. Performance Test of CFT Column Specimen}

In this chapter, the CFT column specimen with the curved ribs on the inner side of the steel pipe is fabricated and the structural performance is examined through the fire test. For this purpose, the evaluation of the 2 - hour fire resistance performance of the uncoated column specimen and the deformation degree and failure mode of the specimen after the test were examined.

\section{A. Fire Test of CFT Column Specimen}

The CFT column specimen was subjected to heating (standard time-heating temperature curve) and load as shown in KS F 2257-1 (General requirements for fire resistance test method of building members)

\section{B. Calculation of Loading load}

The test method was load heating test. Load carrying capacity was $1,800 \mathrm{kN}$, which is $15 \%$ of the nominal strength of the CFT column specimen. There are no clear criteria for loading capacity when we look at the domestic and foreign major standards (KS F 2257-1, JIS A 1304, ASTM E119 12a, ISO 834-1). Therefore, in this study, the fire was considered to be within the allowable stress range because the fire was under normal use load.

\section{Heating and temperature measurement}

The heating of column specimens was carried out according to the heating curve specified in KS F 2257-1. The temperature of the specimens with heating time was measured by installing a K-type $1 \mathrm{~mm}$ thermocouple on the reinforcing ribs and concrete, respectively. The thermocouple was installed at the center of the column, that is, $1.5 \mathrm{~m}$ from the lower end in the longitudinal direction, and was installed at an interval of $20 \mathrm{~mm}$ in the depth direction from the outside of the steel pipe to confirm the temperature change pattern according to the depth of the concrete and the reinforcing rib. Figure 3 shows the connection between the thermocouple sensor and the instrument.

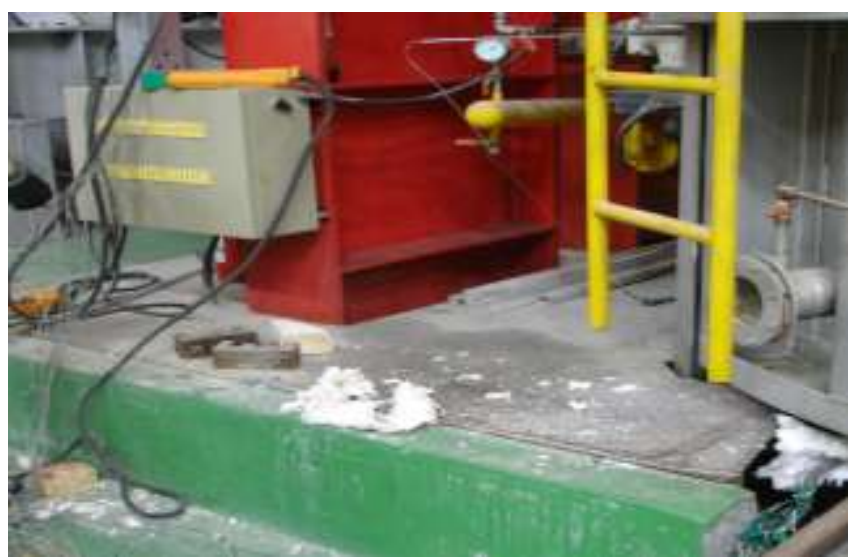

(a) The lower the heating furnace take-off sensor and the fastening

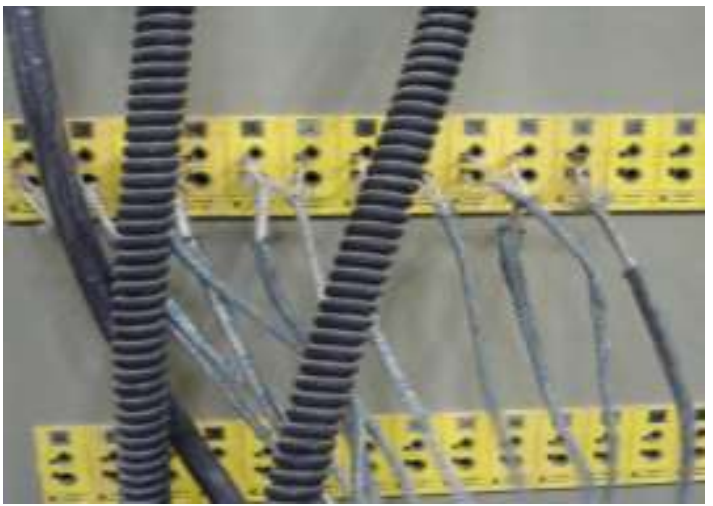

(b) Logger box channel connection

Figure 3. Sensor (thermocouple) connection for temperature measurement

The heating furnace used was a column furnace as specified in KS F 2257-1. The maximum loadable capacity was $10,000 \mathrm{kN}$ and the strain was measured using a linear automatic displacement meter (LVDT). Figure 3 (b) shows the current state of the specimen installed in the column heating furnace and the view during heating.

\section{v. Analysis of Fire Test Results}

\section{A. Temperature Variation}

Table 3 and Figure 3 show the fire test temperature data of the specimen including the standard fire temperature and furnace temperature. Here, $\mathrm{Ch} 2$ and $\mathrm{Ch} 17$ are concrete, and $\mathrm{Ch} 7, \mathrm{Ch} 9$ and $\mathrm{Ch} 12$ are sensors outside and inside the steel pipe at the reinforcing rib position.

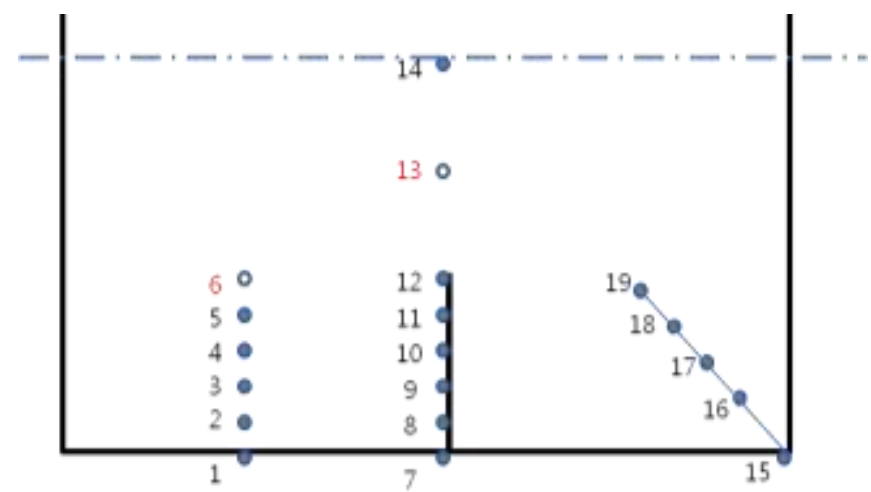

Figure 4. Sensor (thermocouple)

TABLE III. TABLE 3 . FIRE TEST TEMPERATURE DATA (UNIT: ${ }^{\circ} \mathrm{C}$ )

\begin{tabular}{|c|l|l|l|l|l|l|l|}
\hline \multirow{2}{*}{$\begin{array}{c}\text { Time } \\
\text { (minutes) }\end{array}$} & \multirow{2}{*}{$\begin{array}{c}\text { ISO } \\
\mathbf{8 3 4}\end{array}$} & \multirow{2}{*}{$\begin{array}{c}\text { Temp } \\
\text { erature }\end{array}$} & \multicolumn{4}{|c|}{ Internal Sensor Number of Steel pipe } \\
\cline { 7 - 9 } & & & Ch2 & Ch7 & Ch9 & Ch12 & Ch17 \\
\hline 5 & 576 & 570 & 36 & 87 & 37 & 29 & 26 \\
\hline
\end{tabular}


Proc. of Seventh International Conference On Advances in Civil, Structural and Mechanical Engineering -ACSM 2017 Copyright (C) Institute of Research Engineers and Doctors, USA .All rights reserved.

ISBN: 978-1-63248-135-1 doi: 10.15224/ 978-1-63248-135-1-20

\begin{tabular}{|c|c|c|c|c|c|c|c|}
\hline 10 & 678 & 670 & 62 & 177 & 71 & 33 & 31 \\
\hline 15 & 739 & 730 & 85 & 281 & 98 & 94 & 41 \\
\hline 20 & 781 & 777 & 107 & 372 & 103 & 100 & 57 \\
\hline 25 & 815 & 815 & 115 & 460 & 115 & 101 & 76 \\
\hline 30 & 842 & 843 & 146 & 537 & 142 & 102 & 94 \\
\hline 35 & 865 & 867 & 188 & 603 & 175 & 103 & 109 \\
\hline 40 & 885 & 886 & 220 & 662 & 160 & 101 & 128 \\
\hline 45 & 902 & 904 & 253 & 705 & 166 & 103 & 140 \\
\hline 50 & 918 & 919 & 281 & 729 & 197 & 103 & 149 \\
\hline 55 & 932 & 935 & 308 & 759 & 230 & 103 & 176 \\
\hline 60 & 945 & 948 & 333 & 796 & 254 & 103 & 200 \\
\hline 65 & 957 & 960 & 361 & 845 & 274 & 103 & 229 \\
\hline 70 & 968 & 966 & 386 & 829 & 295 & 113 & 256 \\
\hline 75 & 979 & 976 & 409 & 813 & 315 & 123 & 281 \\
\hline 80 & 988 & 992 & 431 & 826 & 334 & 137 & 316 \\
\hline 85 & 997 & 999 & 471 & 842 & 353 & 151 & 372 \\
\hline 90 & 1006 & 1008 & 540 & 842 & 374 & 163 & 406 \\
\hline 95 & 1014 & 1016 & 574 & 850 & 398 & 184 & 438 \\
\hline 100 & 1022 & 1024 & 600 & 860 & 422 & 242 & 464 \\
\hline 105 & 1029 & 1032 & 618 & 880 & 435 & 238 & 478 \\
\hline 110 & 1036 & 1040 & 624 & 970 & 442 & 236 & 490 \\
\hline 115 & 1043 & 1049 & 579 & 833 & 456 & 238 & 493 \\
\hline 120 & 1049 & 1054 & 597 & 857 & 470 & 247 & 505 \\
\hline
\end{tabular}

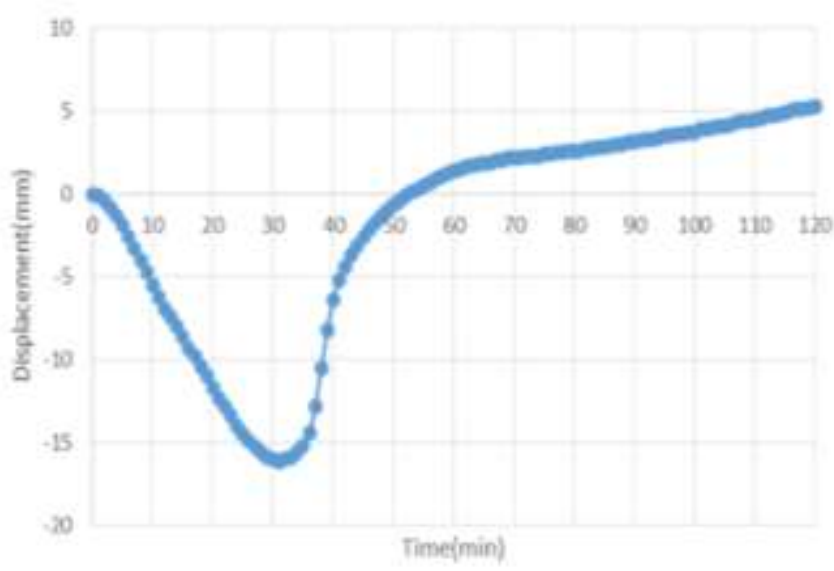

Figure 5. UTM displacement value (2 hour fire resistance test)

\section{B. Temperature Distribution an Alysis result of CFT Column}

Figure 6 shows the temperature history distribution of CFT columns due to fire. As a result of the temperature distribution analysis on the CFT column specimen, the temperature of the center of concrete increased to about $100{ }^{\circ} \mathrm{C}$ after 120 minutes from the start of heating and the surface temperature increased to about $1000{ }^{\circ} \mathrm{C}$. The temperature difference between them was estimated to be about $900^{\circ} \mathrm{C}$. shown in Fig. The CFT column specimens continued to elongate (-) due to thermal expansion, and after about 30 minutes elongation began to decrease (steel temperature about $550{ }^{\circ} \mathrm{C}$ ) and shrinkage (+ value) occurred after about 50 minutes. The temperature distribution of the test specimen shows that the structural deformation has progressed due to the loss of strength of the material at high temperature (steel temperature of about $700{ }^{\circ} \mathrm{C}$, concrete temperature of about $400^{\circ} \mathrm{C}$ ) and cross section loss during the rapid temperature rise
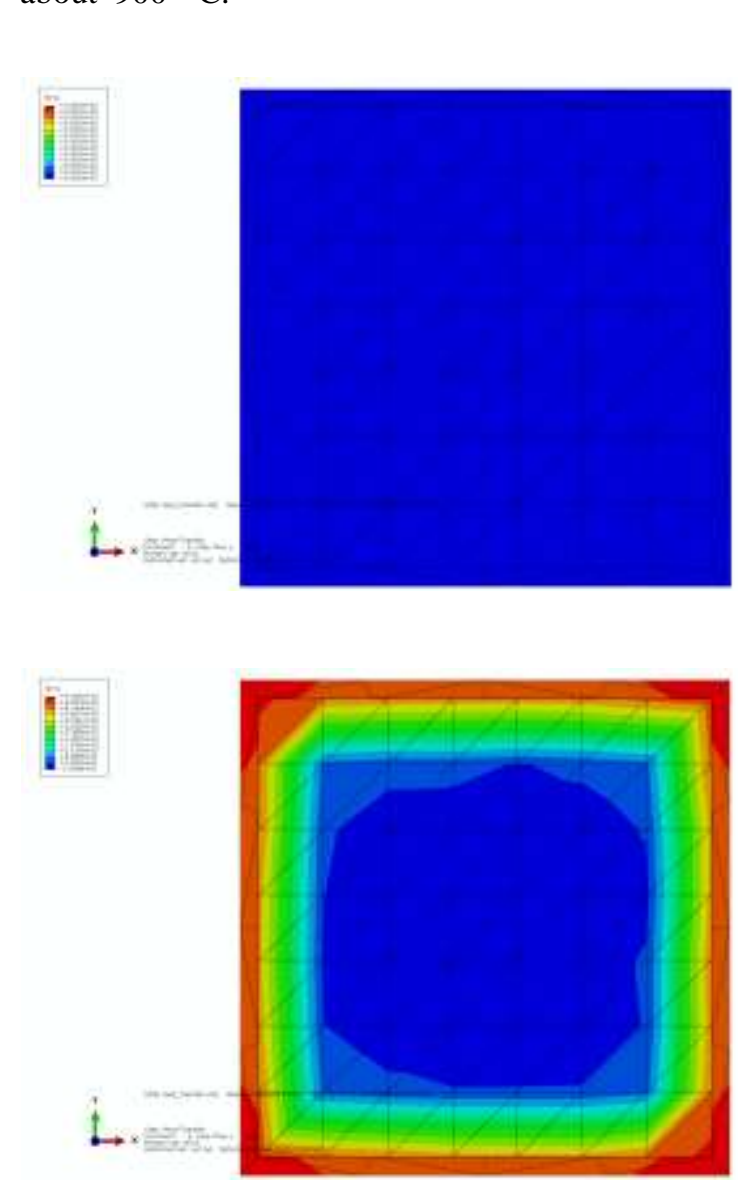


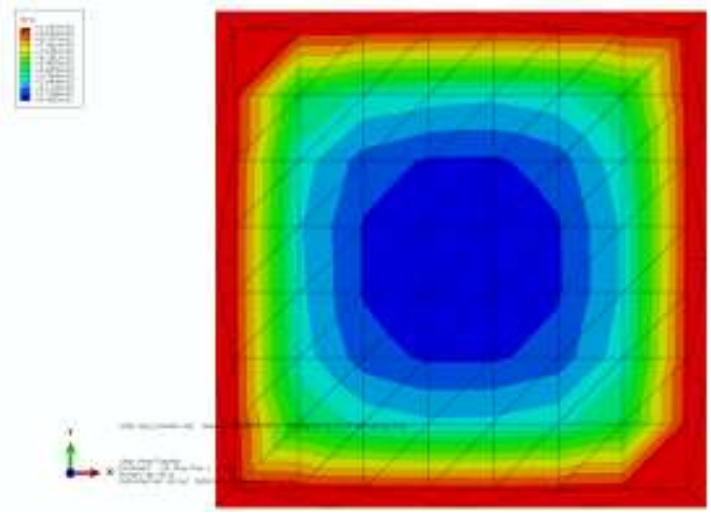

Figure 6. Fire-CFT member end temperature history distribution analysis

One with respect to the cross section of the analytical model in the center of each cross section point a table showing the History Output at each node in the crosssectional center to the outermost outer end is increased, the temperature at a constant rate, the outer end is relatively showed a high initial temperature. In other words, compared to steel pipe surface of the concrete center section it is showing a lower temperature, which indicates that it is not in the center of the heat transfer due to the internal insulation of concrete. The results show that the CFT column can secure the fire resistance for 2 hours in case of fire, and the thermal history analysis results very similar to the experimental results are obtained.

\section{vi. Conclusion}

The CFT(Concrete-Filled steel Tube) column system has many advantages of structural steel and maximizes the benefits of reinforced concrete. As a result, CFT has excellent bending properties and high sectional strength compared with the cross sections of reinforced concrete. However, the weak point of the CFT is the insufficient fire resistance capacity so this system is not widely applicable for real buildings.

CFT sections are used as compressive and flexural members for high-rise buildings and long-span bridges. Since the steel skin confines the outward deformation of the filled-in concrete and concrete resist the inward stress, both steel and concrete enhance the strength of CFT sections. However, there is substantial post-buckling strength in the local mode, and this should be accounted for in estimating the strength of the steel tube. Since the steel skins for CFT columns are usually thin, they are subjected to local buckling. The local buckling of the steel plate which occurs before the collapse of filled-in concrete can affect the ultimate strength of CFT sections. However, most tests have been focused on the behavior and stability of compact CFT sections under axial loading and on the use of high-strength steel and concrete. Fire protection being used as a solution for the fire resistance increases the construction cost, and possibly cause toxic gas when it is subjected to fire. This study focuses on web reinforcement beam which contribute bond strength and also resist to fire for over 2 hour even with no fire protections.
CFT's fire resistance capacity is tested by exposing targeted fire-time temperatures estimated in advance. Testing of the structural member, material, and construction method is conducted in a heating furnace. Fire safety of the structure and construction method, quantitatively evaluated, determines whether it is available to be used. There were number of studies about unprotected CFT columns for improving their fire resistance through reinforcing bars or plates being placed inside the steel tube. But it was also known that the flat type of reinforcing plates need stiffeners in a certain distance to avoid their buckling failure so it cost as much as their using consequentially.

\section{Acknowledgment}

This research was supported by Basic Science Research Program through the National Research Foundation of Korea(NRF) funded by the Ministry of Education, Science and Technology(NRF-2017R1D1A3B05030876)

\section{References}

[1] E.E. Berry, R.T. Hemmings, M.H. Zhang, Hydration in high-volume fly ash concrete binders, ACI Mater. J. (1994) 382-389.

[2] D. Bentz, M. Peltz, a. Duran-Herrera, P. Valdez, C. Juarez, Thermal properties of high-volume fly ash mortars and concretes, J. Build. Phys. 34 (2010) 263-275

[3] P. Duxson, a. Fernández-Jiménez, J.L. Provis, G.C. Lukey, a. Palomo, J.S.J. Deventer, Geopolymer technology: the current state of the art, J. Mater. Sci. 42 (2006) 2917-2933.

[4] P. Duxson, J. Provis, G. Lukey, Understanding the relationship between geopolymer composition, microstructure and mechanical properties, Colloids Surfaces A Physicochem. Eng. Asp. 265 (2005) 47-58.

[5] M. Juenger, F. Winnefeld, Advances in alternative cementitious binders, Cem. Concr. Res. 41 (2011) 1232-1243. 